\title{
WEDGE RESECTION VERSUS LOBECTOMY FOR STAGE I (T1 NO MO) NON-SMALL-CELL LUNG CANCER
}

\author{
Rodney J. Landreneau, $\mathrm{MD}^{\mathrm{a}}$ \\ David J. Sugarbaker, $\mathrm{MD}^{\mathrm{b}}$ \\ Michael J. Mack, MD \\ Stephen R. Hazelrigg, $\mathrm{MD}^{\mathrm{d}}$ \\ James D. Luketich, MD \\ Lynda Fetterman, $\mathrm{RN}^{\mathrm{a}}$ \\ Michael J. Liptay, MD ${ }^{\mathrm{b}}$ \\ Susan Bartley, RNe \\ Theresa M. Boley, RN ${ }^{d}$ \\ Robert J. Keenan, $\mathrm{MD}^{\mathrm{e}}$ \\ Peter F. Ferson, MD \\ Robert J. Weyant, DDS, PhD \\ Keith S. Naunheim, $\mathrm{MD}^{\mathrm{g}}$
}

Background: The role of nonanatomic wedge resection in the management of stage I (T1 NO MO) non-small-cell lung cancer continues to be debated against the present gold standard of care-anatomic lobectomy. Methods: We analyzed the results of 219 consecutive patients with pathologic stage I (T1 N0 M0) non-small-cell lung cancer who underwent open wedge resection $(n=42)$, video-assisted wedge resection $(n=60)$, and lobectomy $(n=117)$ to assess morbidity, recurrence, and survival differences between these approaches. Results: There were no differences among the three groups with regard to histologic tumor type. Analysis demonstrated the wedge resection groups to be significantly older and to have reduced pulmonary function despite a higher incidence of treatment for chronic obstructive pulmonary disease when compared with patients having lobectomy. The mean hospital stay was significantly less in the wedge resection groups. There were no operative deaths among patients having wedge resection; however, a $3 \%$ operative mortality occurred among patients having lobectomy $(p=0.20$ ). Kaplan-Meier survival curves were nearly identical at 1 year (open wedge resection, 94\%; video-assisted wedge resection, 95\%; lobectomy, 91\%). At 5 years survival was $58 \%$ for patients having open wedge resection, $65 \%$ for those having video-assisted wedge resection, and $70 \%$ for those having lobectomy. Log rank testing demonstrated significant differences between the survival curves during the 5-year period of study $(p=0.02)$. This difference was a result of a significantly greater non-cancer-related death rate by 5 years among patients having wedge resection ( $38 \%$ vs $18 \%$ for those having lobectomy; $p=0.014$ ). Conclusion: Wedge resection, done by open thoracotomy or video-assisted techniques, appears to be a viable "compromise" surgical treatment of stage I (T1 N0 M0) non-small-cell lung cancer for patients with cardiopulmonary physiologic impairment. Because of the increased risk for local recurrence, anatomic lobectomy remains the surgical treatment of choice for patients with stage I non-small-cell lung cancer who have adequate physiologic reserve. (J Thorac Cardiovasc Surg 1997;113:691-700)
From the Allegheny General Hospital Campus, a Allegheny University for the Health Sciences, and the Section of Thoracic Surgery, ${ }^{\text {e }}$ School of Dentistry and Biostatistics, ${ }^{f}$ University of Pittsburgh, Pittsburgh, Pa.; the Division of Thoracic Surgery, ${ }^{b}$ Brigham and Womens Hospital, Harvard University Medical School, Boston, Mass.; Division of Cardiothoracic Surgery, ${ }^{\mathrm{C}}$ Medical City Hospital, Dallas, Tex.; Division of Cardiothoracic Surgery, ${ }^{g}$ University of Southern Illinois, Springfield, IIl.; and the Division of Cardiothoracic Surgery, ${ }^{\mathrm{d}}$ St. Louis University Medical Center, St. Louis, Mo.

Read at the Twenty-first Annual Meeting of The Western Thoracic Surgical Association, Coeur d'Alene, Idaho, June 21-24, 1995.

Received for publication June 21, 1996; revisions requested Oct. 31, 1996; revisions received Dec. 11, 1996; accepted for publication Dec. 11, 1996.
$\Lambda$ natomic lobectomy with mediastinal nodal stagAing is the present standard of care for patients with stage I or stage II non-small-cell lung cancer. The potential role of sublobar resection, nonanatomic wedge resection, or segmentectomy as an alternative to lobectomy for the primary management of peripheral stage I lung cancers has been investigated by several surgical groups. ${ }^{1-7}$ A com-

Address for reprints: Rodney J. Landreneau, MD, Section Head, General Thoracic Surgery, Allegheny General Hospital, Suite 302, 490 East North Ave., Pittsburgh, PA 15212.

Copyright (C) 1997 by Mosby-Year Book, Inc.

$0022-5223 / 97 \$ 5.00+0 \quad \mathbf{1 2 / 6 / 7 9 7 8 0}$ 


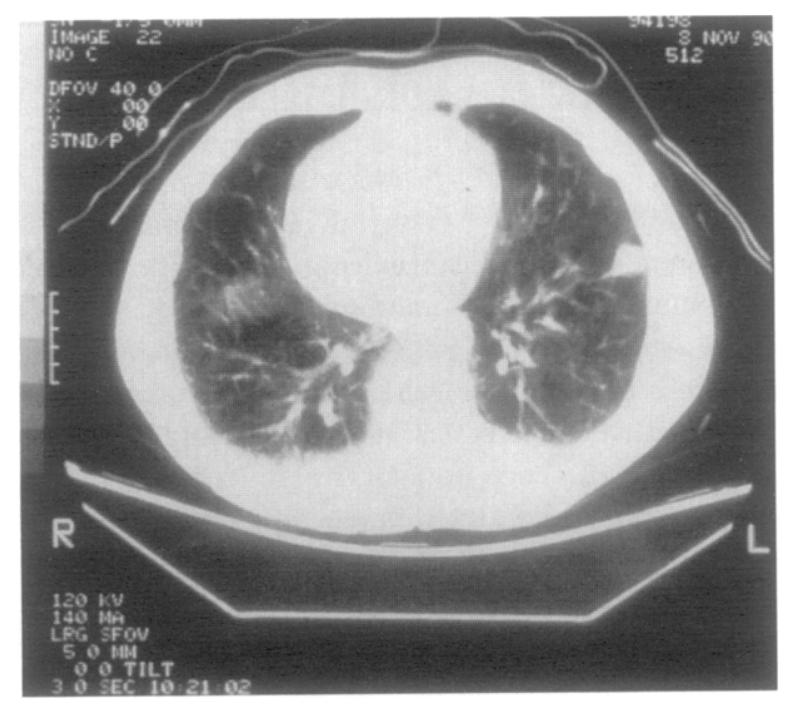

Fig. 1. Typical peripheral T1 N0 non-small-cell lung cancer, which was the focus in this study of wedge resection versus lobectomy.

mon theme throughout these investigations is that the general survival after wedge resection of stage I lung cancers has been equivalent to that of lobectomy but that local recurrence rate has been significantly higher. Because of this local recurrence problem, these "compromise" resections have been primarily directed toward small peripheral lesions found in patients with impairment in cardiopulmonary reserve who are not candidates for lobectomy. $2,6,7$

We have previously demonstrated that the video-assisted thoracic surgical (VATS) approach to pulmonary wedge resection is associated with less patient morbidity and a shorter hospital stay than is wedge resection performed through open thoracotomy. ${ }^{8}$ We and others have also suggested that the VATS approach may have equivalent efficacy to open surgical techniques for the diagnosis and management of a variety of thoracic oncologic conditions. ${ }^{9-11}$ The efficacy of the VATS approach for wedge resection of peripheral lung cancers has not been directly addressed. We chose to compare our results with the VATS approach to nonanatomic wedge resection to open approaches for wedge resection and lobectomy in the oncologic surgical management of $\mathrm{T} 1 \mathrm{~N} 0$ non-small-cell lung cancers. Specific end points related to operative morbidity, local control of the malignant process, and overall patient survival were the focus of this investigation.

\section{Patients and methods}

From January 1989 to July 1994 we treated 219 patients having pathologically determined peripheral stage I (T1 No) non-small-cell lung cancers with surgical resection (Fig. 1). The standard preoperative evaluation centered around a careful history and physical examination, full pulmonary function analyses with blood gas determination, roentgenographic assessment including standard posterolateral chest films, and computed tomography of the chest and upper part of the abdomen. No further metastatic workup was performed routinely; however, other studies were used selectively to investigate specific preoperative symptoms potentially related to metastatic disease.

One hundred seventeen patients underwent anatomic lobectomy through a muscle-sparing thoracotomy. Wedge resection of the primary cancer was performed as primary therapy through a limited lateral muscle-sparing thoracotomy in 42 patients and by using VATS techniques in 60 patients. The decision to use wedge resection as the primary therapy for peripheral lung cancer was related to the surgeon's impression that significant impairment in the patient's physiologic condition precluded lobectomy as a resective option. The age and degree of underlying pulmonary disability in these patients with T1 N0 lung cancer undergoing the various forms of resection (open wedge, VATS wedge, and lobectomy) are noted in Table I. Patients undergoing wedge resection were older and had significantly greater preoperative pulmonary dysfunction necessitating bronchodilator treatment than the patients undergoing pulmonary lobectomy.

To accomplish the open pulmonary resections (lobectomy and wedge resection) in this clinical series, standard axillary, auscultatory triangle, or lateral muscle-sparing thoracotomies were performed with the use of the techniques previously described by several investigators. ${ }^{12,13}$ The axillary muscle-sparing thoracotomy approach was primarily used to approach upper lobe lesions. A lateral muscle-sparing thoracotomy or an auscultatory triangle muscle-sparing approach was used to approach lower lobe, lingular, and middle lobe lesions.

The actual techniques used for open wedge resection and VATS wedge resection in this report have been described by us previously. ${ }^{14}$ With regard to VATS wedge resection, three sites of intercostal access were strategically positioned to allow for the most opportune manipulation of instrumentation about the target area. Endoscopic stapling devices (United States Surgical Corp., Norwalk, Conn., or Ethicon Endosurgical Corp., Cincinnati, Ohio) were used to accomplish the wedge resection in $90 \%$ of the open and VATS wedge resections in this series. The neodymium-yttrium-aluminum-garnet laser (Heraeus Lasersonics Inc., Milpitas, Calif., or Laserscope Inc., model 704, KTP/YA119995, San Jose, Calif.) was used as the primary or ancillary resective tool in approximately $10 \%$ of wedge resections in this series.

Mediastinal and hilar lymph node staging was routinely performed during the surgical management of all patients undergoing resection to ensure that inadvertent inclusion of higher stage cancers did not adulterate this analysis. Radical mediastinal lymph node dissection was not performed. During wedge resection procedures (open and 
Table I. Demographics of age and the percentage of patients who had $T 1$ NO disease and underlying pulmonary disability undergoing the various resections for lung cancer

\begin{tabular}{lccccc}
\hline & Open & VATS & & $p$ \\
& WR & WR & vs & Lobectomy & Value \\
\hline Age (yr) & 68 & 71 & vs & 63 & 0.0002 \\
COPD (\%) & 64 & 69 & vs & 14 & 0.001 \\
FEV $_{1}(\%$ predicted) & 69 & 61 & vs & 88 & 0.0001 \\
DLCO (\% predicted) $^{2}$ & 73 & 51 & vs & 81 & 0.001 \\
\hline
\end{tabular}

$W R$, Wedge resection; $C O P D$, chronic obstructive pulmonary disease; $F E V_{1}$, forced expiratory volume in 1 second; $D L C O$, diffusing capacity for carbon monoxide.

VATS), interlobar lymph nodes were examined and biopsy samples were taken if there was any question of enlargement on preoperative roentgenographic assessment or during intraoperative inspection.

Postoperative care was similar between lobectomy and wedge resection groups but for a few minor exceptions. Patients undergoing lobectomy were admitted overnight to the surgical intensive care unit for observation, whereas most of those having wedge resection were sent to a specialized thoracic surgical stepdown unit immediately after anesthetic recovery. The vast majority of patients undergoing open thoracotomy for wedge resection or lobectomy were managed with postoperative epidural analgesic measures during the early postoperative period. Epidural analgesia was rarely used for patients undergoing VATS wedge resection. Early extubation after reversal of anesthesia was routinely used for all patients. All untoward postoperative events and the total period of postoperative hospitalization were recorded. Complications considered as significant in this analysis included respiratory failure necessitating ventilatory support, empyema, wound infection, air leak greater than 7 days, myocardial infarction/failure, cardiac arrhythmias, and postoperative pneumonia/sepsis. After discharge from the hospital, all patients have been followed up by the operating surgeon in their respective clinics with physical examination and standard posteroanterior chest roentgenograms at 3- to 4-month intervals for the first 2 years after the operation and at 6 -month intervals thereafter. ${ }^{15} \mathrm{Com}-$ puted tomography was only selectively used as a follow-up screening study when the screening roentgenographic studies suggested a new abnormality. Patient follow-up was complete with regard to survival and documentation of recurrence in all patients to within months of this analysis. The median length of documented follow-up for open wedge resection was 29 months; for VATS wedge resection, 24 months; and for lobectomy, 26 months.

Local recurrence was defined as any recurrence of the primary cancer in the hemithorax after wedge resection or any hilar/mediastinal adenopathy in the drainage basin from the lobe in question. With specific regard to patients undergoing lobectomy, local recurrence was defined as new disease in the ipsilateral lung parenchyma, bronchial stump, or the hilar or mediastinal lymph nodes. Local and systemic recurrence was defined as the association of local disease and new roentgenographic, nuclear scintigraphic,
Table II. Wedge resection versus lobectomy for stage 1 (T1 NO MO) Lung Cancer

\begin{tabular}{|c|c|c|c|c|c|}
\hline & $\begin{array}{l}\text { Open } \\
W R\end{array}$ & $\begin{array}{c}\text { VATS } \\
W R\end{array}$ & $v s$ & Lobectomy & $p$ Value \\
\hline $\begin{array}{l}\text { Operative mor- } \\
\text { tality }(\%)\end{array}$ & 0 & 0 & vs & 3.3 & 0.20 \\
\hline $\begin{array}{l}\text { Postop. stay } \\
\text { (days) }\end{array}$ & 7.7 & 6.3 & vs & 10.6 & 0.0002 \\
\hline $\begin{array}{l}\text { Local recurrence } \\
(\%)\end{array}$ & 24 & 16 & vs & 9 & 0.07 \\
\hline $\begin{array}{l}\text { Local/systemic } \\
\text { recurrence }(\%)\end{array}$ & 30 & 26 & vs & 19 & 0.22 \\
\hline
\end{tabular}

or biopsy evidence of metastatic disease outside the ipsilateral hemithorax. Systemic disease alone was defined as the presence of metastatic disease without recurrence within the ipsilateral hemithorax.

Statistical analysis. All statistical analysis was done with SAS Software (SAS Institute, Cary, N.C.) on Macintosh Power PC computers (Apple Computer, Cupertino, Calif.).

Statistical significance for difference among the three treatment groups (i.e., open wedge, VATs wedge, and lobectomy) for each continuous variable was evaluated by means of a one-way analysis of variance. Significant differences in survival times among the three treatment groups were calculated from Kaplan-Meier curves with the use of the log rank test.

In addition, to control for the effect of other factors and to estimate risk ratios, we used the Cox proportional hazard models to examine the effect of treatment on survival times. Specifically, the Cox model considered the effect on survival time of the following explanatory variables: age, tumor size, sex, and treatment type.

\section{Results}

Analyses of the surgical specimens demonstrated that there was no difference in the distribution of histologic types of non-small-cell lung cancers between the wedge resection and lobectomy treatment groups. The median diameter of lesions resected by lobectomy was larger $(2.0 \mathrm{~cm})$ than that of the lesions managed by wedge resection (open wedge, $1.7 \mathrm{~cm}$; VATS wedge, $1.9 \mathrm{~cm}$ ); however, these differences did not reach statistical significance.

The primary oncologic end points focused on in this study were the relative risks for local recurrence and long-term survival after either wedge resection or lobectomy for peripheral T1 N0 non-small-cell lung cancers. The differences in operative mortality and length of hospital stay between wedge and lobectomy groups were also of interest. These results are seen in Table II. Local recurrence did approach significance in favor of lobectomy and operative mortality approached significance favor- 


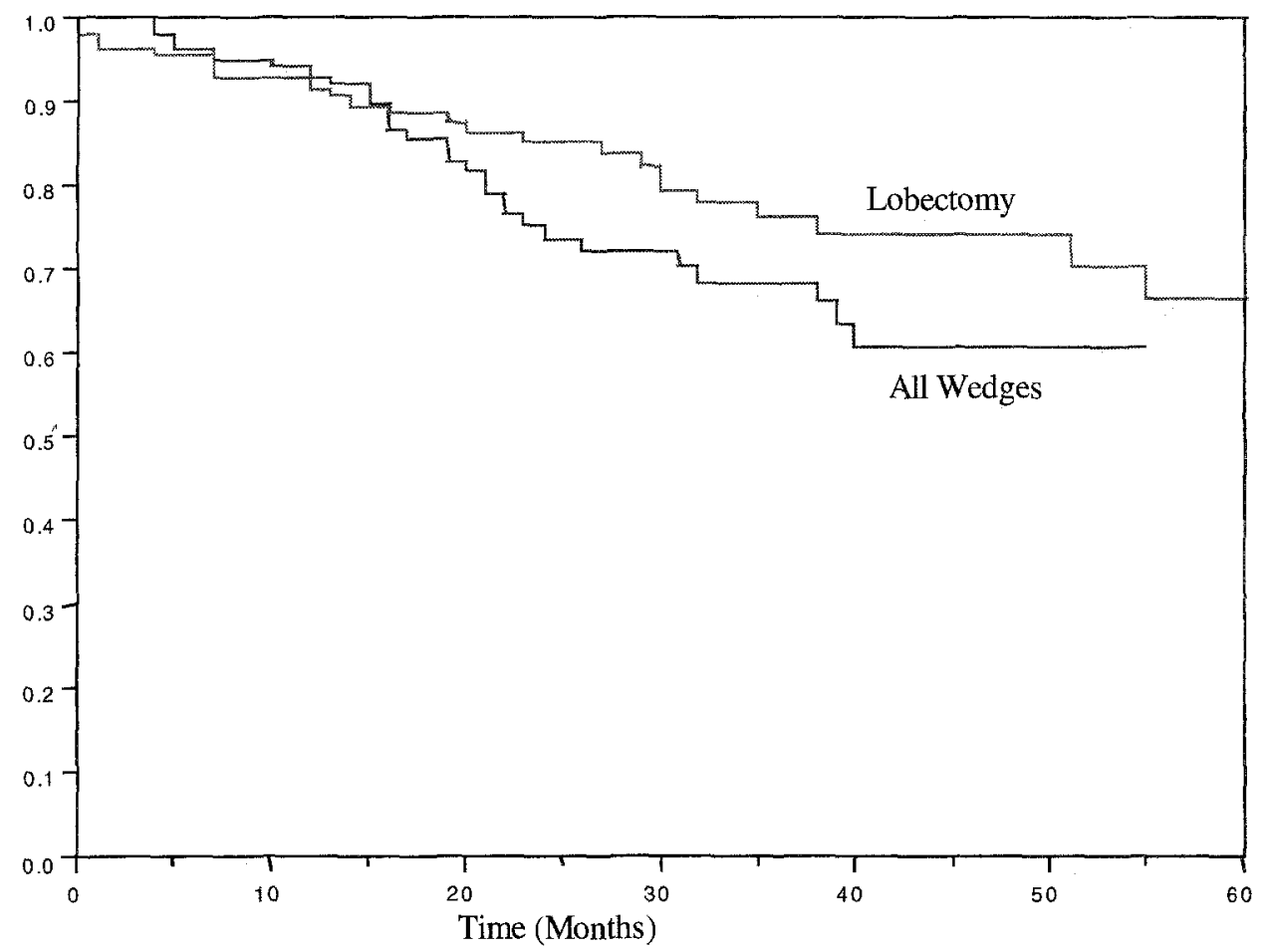

Fig. 2. Five-year actual survival differences noted between all patients having wedge resection and all those having lobectomy.

ing patients undergoing wedge resection. There was, however, no statistically significant difference in the local/systemic recurrence rate between the wedge resection groups and the lobectomy group.

Local recurrence was identified at a median time interval of 10 months among patients having wedge resection and 19 months among those having lobectomy. Only three of the 14 patients in whom local recurrence occurred after wedge resection were considered to be candidates for reresection. The remaining patients were not considered for reresection because of the severity of their cardiopulmonary insufficiency, the presence of an associated malignant pleural effusion, or significant ipsilateral mediastinal adenopathy. Formal segmentectomy was performed in two of these patients and completion lobectomy in the third patient. Reresection was accomplished by completion pneumonectomy in two of the six patients having limited hilar recurrences after lobectomy.

Histologic analysis of the resected tumor revealed no difference in the degree of microscopic angiolymphatic invasion between patients who had a local recurrence and those who have remained free of this. Additionally, the "closeness" of the clear sur- gical margins, determined semiquantitatively by histologic examination, did not appear to discriminate between patients having local recurrence and those not having local recurrence. However, it must be remembered that a clear margin, even if it was "close," had to have been obtained for inclusion in this study.

We also evaluated the occurrence of significant postoperative complications, as defined earlier in the Patients and methods section of this article. Postoperative complications occurred in $16 \%$ of patients having VATS wedge resection in contrast to $28 \%$ of patients undergoing open wedge resection and $31 \%$ of patients undergoing lobectomy $(p<$ 0.05 ).

Although the patient population undergoing wedge resection was generally older, with poorer pulmonary function, the Kaplan-Meier survival proportions for all causes appeared nearly identical at 1 year, and overall survival proportions over the entire 5-year study period did not differ significantly between the wedge resection groups (open wedge/ VATS wedge) and the lobectomy group (Fig. 2, log rank test, $p=0.056$ ). This was primarily the result of an equivalent survival among patients having VATS 


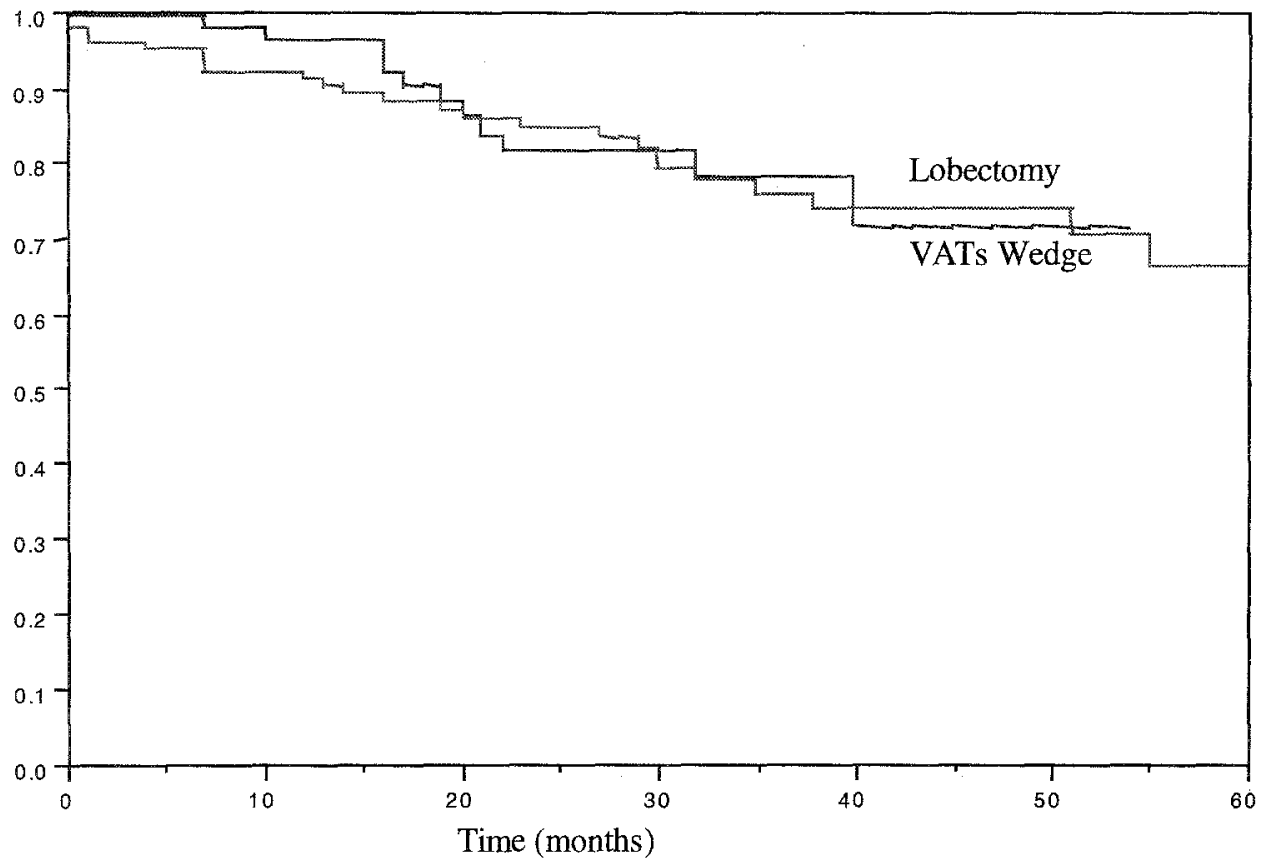

Fig. 3. Five-year actual survival differences noted between patients having VATS wedge resection and those having lobectomy.

wedge resection and those having lobectomy (Fig. 3, $\log$ rank test, $p=0.889$ ). Non-cancer-related deaths were more common among the patients undergoing wedge resection (38\% of deaths) than among those undergoing lobectomy ( $18 \%$ of deaths) $(p=0.014)$. This non-cancer death proportion occurred more commonly in the open wedge resection group, which is exemplified in the survival differences noted between patients having open wedge resection and those having lobectomy (Fig. $4, \log$ rank test, $p=$ 0.005 ).

To control for possible confounding, we created a Cox proportional hazards model that contained the variables tumor size, age, and sex, along with treatment type (lobectomy, VATS wedge, and open wedge resection). After controlling for the effect of these other variables, we found a significant association ( $p=0.042$ ) for treatment type. Specifically, patients undergoing lobectomy had a lower survival than those having VATS wedge resection, although the difference was not significant (risk ratio $=0.80$; $95 \%$ confidence interval 0.49 to 1.24 ); by contrast, the survival in patients having lobectomy was significantly greater than that in patients having open wedge resection (risk ratio $=1.63 ; 95 \%$ confidence interval 1.11 to 2.36 ).

Sex and tumor size showed no significant associ- ation with survival time. The only other significant variable found from the Cox model was age $(p=$ 0.03 ; risk ratio $=1.03 ; 95 \%$ confidence interval 1.002 to 1.066$)$.

\section{Comment}

The history of the evolution of the surgical treatment of lung cancer is interesting. As with the surgical management of other malignant diseases, arguments recorded in the thoracic surgical literature regarding the most appropriate extent of surgical resection needed to properly manage potentially curable carcinoma of the lung have been passionately debated. ${ }^{7,-11,16-22}$ Earlier in this century, pneumonectomy was believed to be the only justified choice for resection in the treatment of carcinoma of the lung. Equivalent survival with lobectomy was reported later by physicians aiming to reduce the morbidity and mortality associated with pulmonary resection for lung cancer. The relative efficacy of sublobar pulmonary resections with respect to patient survival in the treatment of peripheral lung cancers has also been noted. This has particularly been the case for patients who are marginal candidates for any thoracic surgical intervention because of impaired cardiopulmonary function, advanced age, or other significant comorbid 


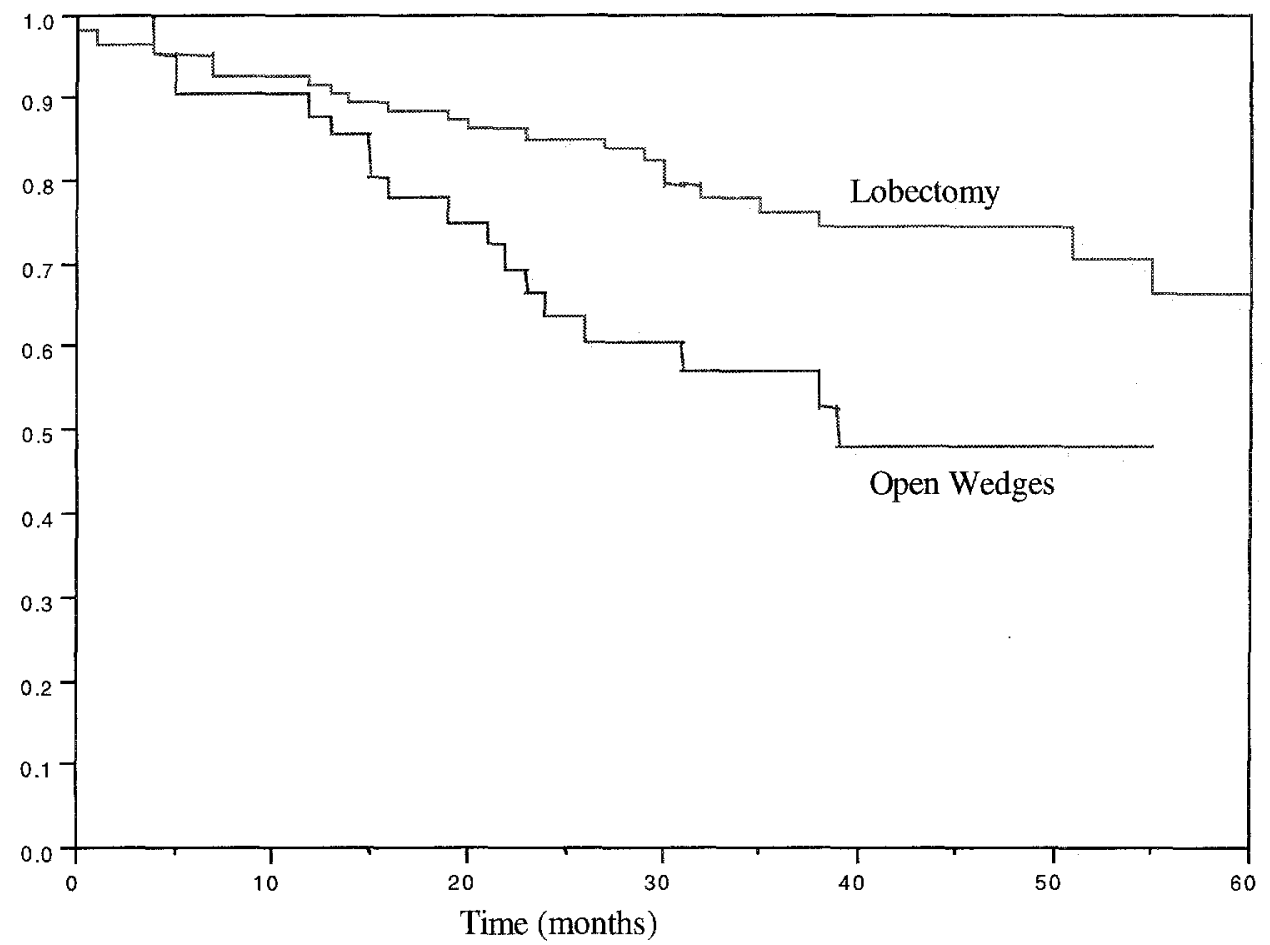

Fig. 4. Five-year actual survival differences noted between patients having open wedge resection and those having lobectomy.

diseases. Indeed, a number of investigations have been reported that document the equivalent survival efficacy of open wedge resection and lobectomy for the management of peripheral $\mathrm{T} 1 \mathrm{~N} 0$ non-small-cell lung cancers. ${ }^{1-7}$ The results of this investigation reaffirm this relative efficacy of wedge resection for small peripheral T1 N0 lung cancers and also for the first time document the relative utility of the VATS approach as a means of accomplishing wedge resection for selected patients with these lesions. It is important to reiterate that the $\mathrm{T} 1 \mathrm{~N} 0$ lesions approached in this investigation were all peripheral and had no bronchoscopic evidence of endobronchial extension. The intraoperative management was also equivalent with regard to intraoperative lymph node staging and assurance that the margins of resection were negative for tumor involvement. The minimum criteria for wedge resection of peripheral lung carcinomas were as follows:

- Less than $3 \mathrm{~cm}$ in diameter (T1 lesion)

- Location in the outer third of the lung and technically approachable by wedge resection (stapled, electrocautery, or laser)

- Absence of endobronchail extension
- Clear margins of resection according to frozen section

- Intraoperative mediastinal and hilar nodal staging

As has been demonstrated before, ${ }^{2}$ this investigation also showed that local recurrence of the malignant process after sublobar resection is greater than that seen after lobectomy. ${ }^{7}$ However, the development of local recurrence after a "clear" resection may more accurately represent a regional manifestation of an aggressive, metastatic phenotype of the malignant tumor, rather than an important failure of our surgical therapy leading to subsequent metastatic disease. ${ }^{23-27}$

The clinical significance of the locally recurrent process has been hard to determine among the physiologically impaired patients for whom wedge resection was chosen in this investigation. To our understanding, death can be attributed to the local recurrence only if the patient dies of massive hemoptysis, sepsis from an obstructing pneumonia or empyema, or local invasion into mediastinal structures by the recurrent tumor leading to massive hemorrhage or cardiac failure. Pulmonary functional difficulty related to diffuse lymphangitic 
spread about a local recurrence may also significantly contribute to the patient's death, but this local process is almost always associated with widespread systemic metastases. The most common occurrence we have witnessed is to have the patient die with local recurrence, but it is rare in our experience to have patients die of the locally recurrent process.

The results of this investigation and those conducted previously should bring us to realize that the primary determinant of long-term survival after "total" surgical excision of T1 N0 lung cancers relates to the biology of the malignant process. $^{28}$ Benfield's comments ${ }^{29}$ on the 1990 manuscript by Read, Yoder, and Schaeffer ${ }^{5}$ probably relate this message best, although his remarks were specifically related to the relevance of lymph node involvement by the malignant process. He stated, ". . .I believe there is ample evidence that lymph node metastasis in cancer is evidence of systemic disease. We thoracic surgeons need to keep up with this modern oncologic concept, lest we continue to focus on lymph node excision as an effective means of cancer control. As in breast cancer, melanoma, colon cancer, and other cancers, lymph node excision is largely of prognostic value-useful for identifying patients who need systemic therapy." Similarly, we might question the importance of total lobectomy for the management of small peripheral T1 N0 lung cancers that can be clearly removed by a generous wedge resection.

Because of the increased risk of local recurrence, at this time we continue to use lobectomy as our primary means of resection of peripheral T1 N0 lung cancers identified in good-risk patients. Although the postoperative morbidity and mortality with lobar resection is relatively small, ${ }^{30}$ these negative postoperative consequences may be more important than the development of a local recurrence that may primarily be the harbinger of an aggressive malignant phenotype. Certainly for the patient with physiologic impairment, wedge resection accomplished by open thoracotomy or VATS appears to be a valid management alternative to lobectomy for appropriately selected peripheral T1 N0 lung cancers.

\section{REFERENCES}

1. Keagy BA, Pharr WF, Bowes DE, Wilcox BR. A review of morbidity and mortality in elderly patients undergoing pulmonary resection. Am Surg 1984;50:213-6.

2. Miller JI, Hatcher CR. Limited resection of bronchogenic carcinoma in the patient with marked impairment of pulmonary function. Ann Thorac Surg 1987;44:340-3.
3. Jensik RJ. Miniresection of small peripheral carcinomas of the lung. Surg Clin North Am 1987;67:951-8.

4. Erret LE, Wilson J, Chiu RC-J, Munro DD. Wedge resection as an alternative procedure for peripheral bronchogenic carcinomas in poor-risk patients. J Thorac Cardiovasc Surg 1985;90:656-61.

5. Read RC, Yoder G, Schaeffer RC. Survival after conservative resection for T1 N0 M0 non-small cell lung cancer. Ann Thorac Surg 1990;49:242-7.

6. Pastorino U, Valente M, Bedini V, Infante M, Tavecchio L, Ravasi G. Limited resection of stage I lung cancer. Eur J Surg Oncol 1991;17:42-6.

7. Lung Cancer Study Group, Ginsberg RJ, Rubenstein LV. Randomized trial of lobectomy versus limited resection for T1 N0 non-small cell lung cancer. Ann Thorac Surg 1995;60: $615-23$.

8. Landreneau RJ, Hazelrigg SR, Mack MJ, Perrino MK, Nunchuck S, Ritter PS, et al. Postoperative pain-related morbidity: video-assisted thoracic surgery vs thoracotomy. Ann Thorac Surg 1993;56:1285-9.

9. Lewis RJ. The role of video-assisted thoracic surgery for carcinoma of the lung: wedge resection to lobectomy by simultaneous individual stapling. Ann Thorac Surg 1993;56: $762-8$.

10. Shennib H, Landreneau RJ, Mack MJ. Video assisted thoracoscopic wedge resection of $\mathrm{T} 1$ lung cancer in high risk patients. Ann Surg 1993;218:555-60.

11. Landreneau RJ, Mack MJ, Hazelrigg SR, Naunheim KS, Keenan RJ, Ferson PF. The role of video-assisted thoracic surgery in thoracic oncologic practice. Cancer Invest 1995; 13:526-39.

12. Hazelrigg SR, Landreneau RJ, Boley TM, Priestmeyer ML, Schmaltz RA, Nawarawong W, et al. The effect of muscle sparing versus posterolateral thoracotomy on pulmonary function, muscle strength and postoperative pain. J Thorac Cardiovasc Surg 1991;101:394-401.

13. Fry WA. Thoracic incisions. Chest Surg Clin North Am 1995;5:177-88.

14. Landreneau RJ, Mack MJ, Hazelrigg SR, Dowling RD, Acuff TE, Magee MJ, et al. Video assisted thoracic surgery: basic technical concepts and intercostal approach strategies. Ann Thorac Surg 1992;54:800-7.

15. Pairolero PC, Williams DE, Bergstralh EJ, Piehler JM, Bernatz PE, Payne WS. Postsurgical stage I bronchogenic carcinoma: morbid implications of recurrent disease. Ann Thorac Surg 1984;38:331-8.

16. Ochsner A, DeBakey M. Surgical considerations of primary carcinomas of the lung: review of the literature and report of 19 cases. Surgery 1940;8:991-1023.

17. Churchill ED, Sweet R, Soutter L, Scannell JG. The surgical management of carcinoma of the lung: A study of cases treated at the Massachusetts General Hospital from 1930 to 1950. J Thorac Cardiovasc Surg 1950;20:249-65.

18. Overholt RH, Langer L. A new technique for pulmonary segmental resection: its application in the treatment of bronchiectasis. Surg Gynecol Obstet 1947;84:257-68.

19. Reinhoff WF Jr. Present status of surgical treatment of primary carcinoma of lung. JAMA 1944;126;1123-8.

20. Iascone C, DeMeester TR, Albertucci M, et al. Local recurrence of resectable non-oat cell carcinoma of the lung. Cancer 1986;57:471-6. 
21. Ginsberg RJ. Thoracoscopy: a cautionary note. Ann Thorac Surg 1993;56:801-3.

22. Cooper JD. Perspectives on thoracoscopy in general thoracic surgery. Ann Thorac Surg 1993;56:697-700.

23. Siegfried JM, Gaither-Davis AL, Testa JR, Hunt JD, Keenan RJ, Yousem SA, et al. Ability to culture resectable non-small cell lung carcinomas is correlated with recurrence. Ann Thorac Surg 1994;58:662-7.

24. Kessler R, Gasser B, Massard G, Roeslin N, Meyer P, Wihlm $\mathrm{J}-\mathrm{M}$, et al. Blood vessel invasion is a major prognostic factor in resected non-small cell lung cancer. Ann. Thorac Surg 1996:62:1489-93.

25. Siegfried JM, Singh-Kaw P, Landreneau RJ. Elevated hepatocyte growth factor is associated with poor prognosis in lung adenocarcinomas. Respir Critic Care Med 1995:151:A279.

26. Harpole DH, Richards WG, Herndon JE, Sugarbaker DJ. Angiogenesis and molecular biologic substaging in patients with stage I non-small cell lung cancer. Ann Thorac Surg 1996;61:1470-6.

27. Johnson JR, Bonfield JR, Hammond WC, Tesluk H. Successful xenotransplantation of human non-small cell lung cancer correlates with the metastatic phenotype. Ann Thorac Surg 1995;60:32-7.

28. Benfield JR. The lung cancer dilemma. Chest 1991;100:510-1.

29. Benfield J. Comment on Read et al. ${ }^{5}$

30. Deslauriers J, Ginsberg RJ, Piantadosi S, Fournier B. Prospective assessment of 30-day operative morbidity for surgical resections in lung cancer. Chest 1994;106:329S-30S.

\section{Discussion}

Dr. James B. Mark (Stanford, Calif.). Dr. Landreneau and his coauthors have tried to answer another important question - whether wedge resection, thoracoscopic or open, is as good as lobectomy in the treatment of stage I lung cancer. They have amassed 219 patients from five institutions over a $5 \frac{1}{2} 2$-year period, or eight patients per institution per year, so those of us who do relatively few such operations do not have to feel too far behind.

Pooling patients and data has certain advantages. What the authors tell us is that even though the rate of local recurrence is greater with wedge resection than with lobectomy, the actuarial survival is insignificantly different in the two groups at 4 years. Presuming that local recurrence means that cure is not possible, these figures must mean that if there is no local recurrence there is a greater chance of a systemic recurrence or that lobectomy itself causes more systemic recurrences. I have a hard time sorting all that out.

In Table II of the article there are some things that to my mind are counterintuitive. The operative mortality of $0 \%$ for the wedge resections versus $3.3 \%$ for the lobectomies is not significant except to the four patients who died. The $30 \%$ to $50 \%$ difference in postoperative stay between the wedge resection and lobectomy groups, however, is highly significant. There is a $40 \%$ difference in local/ systemic recurrence (not significant) and an insignificant difference in local recurrences (between 5\% in lobectomies and $15 \%$ or $17 \%$ in wedge resections). Dr. Grunkemeier is now a member of our organization, and I hope he is present and can explain this, because I really do not understand the statistics. I do not doubt them; I just do not understand them.
I have a few technical questions. The first involves intraoperative lymph node staging. I know that I can do a better job of lymph node dissection in the paratracheal and subcarinal regions with the chest wide open than I can thoracoscopically or through a limited incision. I would like to hear a little more about the technique and extent of lymph node sampling or dissection used by the authors when they do VATS or open wedge resection or even lobectomy.

Dr. Landreneau. Regarding the statistical analysis, Dr. Mark, the local recurrence rate was 0.07 , which approached significance. These numbers were affected by the relatively small sample sizes involved with recurrences in all groups. The local/systemic resistance was also insignificant $(p=0.22)$.

Dr. Mark. But that is a $40 \%$ difference between $23 \%$ and $24 \%$ on the one hand and $17 \%$ on the other hand. There is a $40 \%$ difference in recurrence rates between the wedge resections and the lobectomies.

Dr. Landreneau. With regard to nodal staging and sampling, stations from levels 4 and 7 were routinely evaluated and also sampled in both the VATS and open wedge resection groups. The hilum was explored, and if no obvious disease was palpated a biopsy was not undertaken.

Our philosophy was similar with regard to open resection. We did not routinely sample hilar nodes with the lobectomy specimens. They were looked at. The hilar nodes that were removed were part of the tissue within the block of resection that was associated with the lobectomy. Again, biopsy samples of stations 4 and 7 were routinely taken in all circumstances. I would assume that there is some stage II disease in our wedge resection group or stage III disease that may have been occult, yet the survival was similar. Understanding this, the survival pattern seen here may be more reflective of the biology of the disease rather than the importance of an aggressive nodal resection.

Dr. Mark. What you are saying is that, like Dr. Benfield, you believe that if there is lymph node extension it is not really worth resecting those lymph nodes. In other words, sample them to find out if there is "systemic disease," but do not include lymph node dissection as part of either wedge resection or lobectomy.

Dr. Landreneau. I think that is the consensus of our group.

Dr. Mark. There is a small difference in opinion.

Second question: What is the definition of adequate sublobar resection? You mention clear surgical margins. How clear is clear? Are frozen sections done on all resected specimens and all nodes? How wide a margin do you consider adequate around a $\mathrm{T} 1$ or even $\mathrm{T} 2$ tumor?

Dr. Landreneau. The latter part of your question is indeterminate as far as $5 \mathrm{~mm}, 1 \mathrm{~cm}$, or whatever as being adequate. Frozen section analysis was performed, and the results were confirmed by the final pathologic assessment for permanent section analysis that the margins were clear in these circumstances. Obviously, if the local recurrence rate is increased, some cells are being left in transit within the lymphatics. What does that mean for the patient's prognosis? The biggest issue, in my mind, is determining the importance of local recurrence as it affects patient 
survival. Is it a primarily important variable or simply a harbinger of a virulent malignant process?

Dr. Mark. The third and last question: In patients who are going to have a wedge resection, how do you decide whether to use the thoracoscopic or open technique?

Dr. Landreneau. Our bias is to perform wedge resections thoracoscopically for peripheral small lesions. Deeper lesions would not have been included in this study. A peripheral lesion can be safely encompassed without violation of the visceral or deep margins of the resection.

Dr. Mark. You did as many open wedge resections as you did thoracoscopic wedge resections in this group. Why did you do any open wedge resections for peripheral lesions that could have been removed thoracoscopically?

Dr. Landreneau. In general, open wedge resection was done earlier in each surgeon's reported experience here. Some of us moved to the VATS approach earlier than others, leading to some overlap in the VATS and open wedge approach. The lesion characteristics for inclusion (peripheral T.1 lesions) into this analysis were universally applied. At this time, most all of these lesions are approached with VATS when wedge is being considered.

Dr. Mark. You have done very well with this analysis as far as you go, and I believe you add to our comfort level when we do wedge resections of peripheral lung cancers in poor-risk patients, as suggested by Jensik and others some years ago. I am not yet prepared to do wedge resections in good-risk patients, nor apparently are you. The adjuvant therapy is not as good as we would like it to be, certainly not as good as it is in breast cancer. I am not even sure that open wedge resection is safer than lobectomy in some poor-risk patients. In fact, you performed a second operation in a few of your poor-risk patients who had local recurrence after wedge resection, and in one of those patients the operation was a lobectomy. I continue to do wedge resections thoracoscopically if technically feasible in poor-risk patients. At the moment only clinical judgment separates the good-risk from the poor-risk category. There is still a place for a properly controlled and randomized study to definitively answer the questions.

Dr. Robin Cohen (Los Angeles, Calif.). When we started using VATS for wedge resections for cancer, we noticed not only that were we getting local recurrences but also that they seemed to come early, many of them in less than a year. We attributed this to technical factors. Can you comment on that? Also, what do you tell the patients knowing that they have a significant chance of local recurrence after wedge resection? What kind of time course do you expect? Were there any differences in time between the open wedge resections and the VATS wedge resections?

Dr. Landreneau. In the wedge resection group the median time of recurrence was around 11 months. In the lobectomy group recurrence was recognized at about 19 months. The difference between the groups was significant. We had the impression that we might have unleashed some local factors, such as trauma, that provided a milieu in which the residual tumor could grow. That is speculation. However, because of the nature of the resection, there is parenchyma around the area that was removed that allowed us to identify the disease earlier than following lobectomy where appreciation of local recurrence can be delayed until new hilar prominence on bronchial stump recurrence is noted. There was no differ ence in local recurrence between the open wedge resection group and the VATS group.

To answer another of your questions, these patients generally had more physiologic impairment, and they knew that we were doing a sublobar resection because of their physiologic impairment. They were informed of the increased risk for local with the wedge resection approach. Lobectomy continues to be our standard of care for good-risk patients with $\mathrm{T} 1$ lesions, although I have some question as to whether lobectomy is necessary for the management of the $1 \mathrm{~cm}$ very peripheral lesion.

Dr. John R. Benfield (Sacramento, Calif.). I have just reviewed the Lung Cancer Study Group manuscript, which will be appearing in the Annals of Thoracic Surgery. My recollection is that there is not a true survival difference and that it is arguable as to whether there is a true survival difference. The main argument is the local recurrence issue. In this era of outcomes research, it would be extraordinarily important for us to know what a local recurrence really meant to the patients. Did they have reoperations? Did those local recurrences really contribute to their death? Did those local recurrences interfere with their quality of life? Would it have been worth doing a large operation to avoid a possible local recurrence in those patients? Those are the questions that have to be answered, in addition to the hard statistic of whether or not a local recurrence occurs.

Dr. Landreneau. I agree with you wholeheartedly. In most patients in this group (60\% of the 17 patients who had a recurrence) the recurrence caused no symptomatic problem, and it was later identified that these patients died of systemic disease. The problem in the other $30 \%$ or so of the patients was chest wall pain. Although compromised, we felt reresection was indicated. Thus there were only three of 17 patients whom we thought we could potentially help with reresection. We did not think a second resection useful in the others because of their impaired physiology. Our definition of local recurrence was any disease recurrence within the ipsilateral hemithorax, a very broad definition.

Dr. Benfield. You stated that your margins of resection were clear in all cases. Were there instances in which the margins were so close that you reresected additional tissues to be sure that you had a free margin or in which a reresection at the time of the initial operation was required to achieve a free margin?

Dr. Landreneau. It was a patient selection issue. There were circumstances in which, after firing the endoscopic stapler during a VATS wedge, we realized that the base of the margin would be compromised. Conversion to an open wedge approach followed. Better control of the lung parenchyma beneath the lesion was obtained for the stapler and on laser resection. A subset of these patients were treated with laser resection before the endoscopic stapling devices became readily available, and several of the specimens were said to have close margins. I looked at the close margins versus distant margins and saw no difference in the incidence of local recurrence. Histologic findings of lymphangitic spread within the specimen also had no effect on local recur- 
rence. Those are the things I was hoping to find as identifiers of local recurrence, but I could find nothing in the limited analysis we had.

Dr. Arthur N. Thomas (San Francisco, Calif.). I have found that it is much more difficult to do a thoracoscopic wedge biopsy if the lesion is at all deep in the lung. In fact, in some of the wedge excisions the true margin is really not the width of the wedge. Rather, the lesion is subserosal and you are really looking at a couple high-power fields between the tumor and the surface of the lesion. Is your decision to do an open or a VATS technique influenced by that sort of factor and might that be related to the recurrences in the patients undergoing VATS techniques?
Dr. Landreneau. If there was any possibility, based on visceral pleural involvement, that the lesion was a T2 lesion, the patient was excluded from this analysis, and the stage of disease was determined by the final pathologic evaluation. We were dealing with lesions that were technically feasible for VATS resection. The clinical judgment issue that Dr. Mark brought up is paramount in deciding whom you can and cannot treat in this fashion. Patients with deeper lesions were not treated by wedge resection and were also excluded from the lobectomy group in this analysis. We were dealing with small T1 lesions, with a mean size of less than $2 \mathrm{~cm}$, that were anatomically feasible for wedge resection in these circumstances.

\section{Availability of Journal back issues}

As a service to our subscribers, copies of back issues of The Journal of Thoracic and Cardiovascular Surgery for the preceding 5 years are maintained and are available for purchase from Mosby at a cost of $\$ 15.00$ per issue until inventory is depleted. The following quantity discounts are available: $25 \%$ off on quantities of 12 to 23 , and one third off on quantities of 24 or more. Please write to Mosby-Year Book, Inc., Subscription Services, 11830 Westline Industrial Drive, St. Louis MO 63146-3318, or eall 800-453-4351 or 314-453-4351 for information on availability of particular issues. If unavailable from the publisher, photocopies of complete issues may be purchased from UMI, 300 N. Zeeb Rd., Ann Arbor, MI 48106, 313-761-4700. 